

\section{DISCLAIMER}

This report was prepared as an account of work sponsored by an agency of the United States Government. Neither the United States Government nor any agency Thereof, nor any of their employees, makes any warranty, express or implied, or assumes any legal liability or responsibility for the accuracy, completeness, or usefulness of any information, apparatus, product, or process disclosed, or represents that its use would not infringe privately owned rights. Reference herein to any specific commercial product, process, or service by trade name, trademark, manufacturer, or otherwise does not necessarily constitute or imply its endorsement, recommendation, or favoring by the United States Government or any agency thereof. The views and opinions of authors expressed herein do not necessarily state or reflect those of the United States Government or any agency thereof. 


\section{DISCLAIMER}

Portions of this document may be illegible in electronic image products. Images are produced from the best available original document. 
ANNUAL PROGRESS REPORT

\author{
ON \\ STUDIES OF AIR POLLUTION EFFECTS \\ ON VEGETATION
}

in progress at

LAWRENCE LIVERMORE LABORATORY

Environmental Sciences Division

Prepared for: Dr. J. S. Jacobson

Division of Biomedical and Environmental Research

U. S. Department of Energy

Washington, D. C.

\title{
January 1978
}

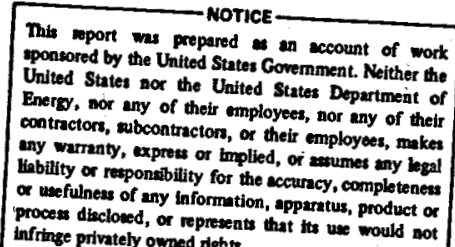


REPORT CONTRIBUTORS
Part I.
Patrick I. Coyne
Gail E. Bingham
Part II. Joseph S. Shinn
Part III. Joseph S. Shinn 
CONTENTS

Page

Preface .......................... $\mathbf{i} \mathbf{i}$

Project Reports

Effects of Air Pollution on Western Plant Ecosystems:

Effects of Oxidant on Primary Productivity in Ponderosa

Pine in the San Bernardino National Forest (RPIS \#000699) . . 1

Figures for RPIS \#000699 ............ 20A-20E

Air Pollution Effects on Vegetation From Geothermal Development

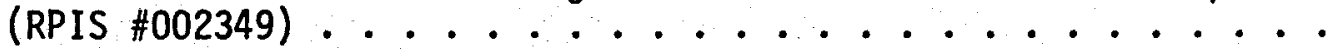

IVEP Geotherma1: Integrated Assessment (Crop Effects Modeling

Tasks) (RPIS \#002349) ................ 27

Publications and Manuscripts ............ 30-33

Extra-curricular Involvement ................ 34

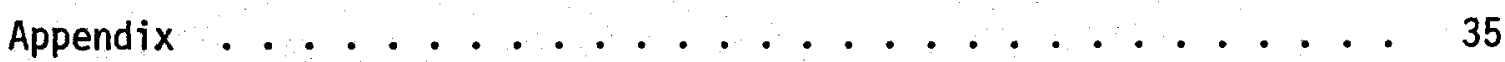




\section{PREFACE}

This report was prepared to satisfy the requirements specified by by Dr. J. S. Jacobson DBER/DOE and transmitted in his memo dated 5 December 1977.

The report consists of three parts which summarize pollutant-vegetation effects studies supported under three separate Schedule 189's. These include: Part 1 - 0xidant Effects of Primary Productivity in Ponderosa Pine in the San Bernardino National Forest (RPIS \#000699); Part 2 - Air Pollution Effects on Vegetation Related to Geothermal Power Development (RPIS \#002342); and Part 3 - Regional Assessment of Air Pollution Impact on Vegetation by Mathematical Modeling (RPIS \#002349).

Traditionally, only the San Bernardino study would be reviewed to satisfy the objectives of this report. However, we have elected to include the other two parts to more accurately portray our total capability to conduct integrated research even though our funding structure to date has necessitated a discontinuous approach. 
I. Effects of Oxidant On Primary Productivity In Ponderosa Pine In The San Bernadino National Forest (RPIS \#000699)

\section{Review of Research Scope}

The general objective which has guided our research is the need to develop a rational method to assess air-pollution effects on plant ecosystems in the western United States. Chronic low doses of air pollution, such as occurs in basins of western states containing power plants and industrial and urban development, continues to cause deleterious metabolic responses in plants which translate into economic loss, undesirable changes in population dynamics, and loss of esthetic value. Ascribing a monetary figure to these losses is difficult even in agricultural situations but is often impossible in natural systems. In the state of California alone, estimates of damage to agriculture resulting from a air pollution is approaching $\$ 100$ million. Not included in this type of estimate are all the costs incurred by growers and scientists in their attempts to offset pollution-related yield reductions through improved cultural and management practices, improved genetic stock, and greater uses of fertilizer and fossil energy.

Our specific objectives have been 1) to develop a field and laboratory capability to characterize effects of introduced environmental stresses on plant function in the context of interacting natural environmental stresses (1ight, temperature, water, nutrition, etc.) and 2) to use these capabilities 
to obtain data which will answer basic physiological questions on mechanisms of stress action and plant resistance to the stress as well as applied questions of an assessment and predictive nature.

Our current application is primarily addressed to oxidant stress effects. But it should be emphasized that our approach is equally applicable to any introduced plant stress and is, therefore, relevant to all energy technologies and their accompanying emissions, both gaseous and particulate. Seldom, if ever, do stress factors act alone. Thus, we have placed considerable emphasis on the capability to evaluate interactions among natural and introduced stresses. It is highly likely that sulfur pollutants will become increasingly important in the west in the foreseeable future as natural gas supplies diminish and the power utilities become more dependent on coal and geothermal. Sulfur pollution stress will be superimposed on a system already stressed by oxidant. We have already begun incorporating $\mathrm{H}_{2} \mathrm{~S}$ and $\mathrm{SO}_{2}$ effects into our studies.

To accomplish our objectives, we have developed a program which centers around the process of photosynthesis and stomatal function. Photosynthesis is particularly relevant for several reasons. It is central to organic matter production and is, therefore, the driving force in the functioning of any ecosystem and the basis for economic yield. Success of a plant in any environment with its complement of interacting stresses will probably depend on its ability to gain resources (energy, carbon, nutrients) and on how it allocates these resources. Photosynthesis is particularly sensitive to chronic airpollution and generally responds prior to the development of foliar symptoms. Equally important is that it is conducive to precision characterization by 
measurement of $\mathrm{CO}_{2}$ and water vapor exchange between the leaves and the ambient environment under conditions of controlled temperature, humidity, and 1ight. Finally, the photosynthetic process can be modeled theoretically which expands the predictive capabilities beyond the limits of the data base. Considerable published modeling work is already available so that our task can be directed more to incorporating pollutant effects into these existing models rather than to basic model development.

In addition to $\mathrm{CO}_{2}$ exchange, it is essential to simultaneously measure water vapor exchange and leaf water potential. Leaf water potential controls stomatal response to 1 ight and is on indicator of the degree of water stress experienced by the plant. Water vapor exchange data allow calculation of the degree of stomatal opening (diffusive resistance or its reciprocal conductance). This is one of the most important parameters that can be measured in air-pollution studies. Not only does stomatal resistance exert direct control on photosysthesis through its regulation of $\mathrm{CO}_{2}$ diffusion, it also determines the movement of pollutant into the leaf interior. External pollutant concentration has little meaning if the stomates are closed. Stomatal resistance must be known to calculate internal concentrations of pollutant gases. Water vapor exchange data also contribute to the process of partitioning the $\mathrm{CO}_{2}$ diffusion pathway which in turn allows meaningful indices of water use efficiency to be calculated. This is particularly relevant to air pollution effects studies in the arid west. Since water stress can greatly alter a plants response to pollution, its effects must be characterized in any mechanistic modeling effort.

We do not view photosynthesis as the end result of our approach, particularly in those cases where economic yield is the most meaningful index of pollutant damage. Photosynthesis should be highly correlated with biological yield and 
survival, but allocation of the avialable photosynthate pool will determine economic yield. Where economic yield is of prime concern, concurrent studies of energy allocation strategies as a function of environmental stress must be conducted and the data used to parameterize an allocation model. The photosynthesis model can then be used to predict the time course of photosynthate pool size and the allocator can be used to partition the pool among growth, maintenance, and yield. While the effects of pollutant concentrations and mixtures on yield can be predicted from more easily derived empirical relationships, the mechanistic modeling approach incorporating photosynthesis and allocation is superior for predicting impact under conditions which lie beyond the limits of the empirical data base. In addition, the model allows system sensitivities to environmental factors to be evaluated and it can serve as a tool to direct research into areas showing high sensitivity but where our mechanistic understanding is weakest.

In the San Bernardino National Forest (SBNF) study, we have purposely concentrated on the photosynthes is response and have not devoted any effort to energy allocation. Although managed as a multiple-use resourse, the low annual precipitation and the close proximity of the SBNF to the greater Los Angeles area has resulted in recreation being the predominant use and timber production being of much less importance economically. The SBNF, consistently, has been the most frequently visited national forest in the United States with 6 million visitors in 1973. We did not have the resources and facilities to undertake detailed photosynthate allocation studies of a Jarge forest tree species at a remote site. Because of these constraints, we felt justified in restricting our efforts to photosynthes is since from a recreational and esthetic 
viewpoint, survivability and reproduction rather than production of marketable timber were of primary importance.

Variability in response to oxidant by the ponderosa pine populations has, in general, been stratified into damage or survivability classes by agencies studying the impact of oxidant on the entire forest ecosystem. We feel that development of a relationship between photosynthesis behavior among trees in different damage classes and survivability will bear directly on population dynamics models being synthesized by other agencies. However, any work we may do in the future on agronomic species will necessarily incorporate allocation studies. We expect to have on-line a highly-controlled environmental growth facility with pollutant exposure capability by mid-1978. This facility will be ideally suited for gas exchange and energy allocation studies.

The chronology of tasks originally envisioned for the SBNF program were 1) development of intensive and extensive systems for field and laboratory measurements of gaseous exchange $\left(\mathrm{CO}_{2}\right.$, water vapor) under controlled conditions, 2) characterization of seasonal changes in the photosynthetic and stomatal light responses of different ponderosa pine oxidant damage classes for conditions of minimal water stress and optimum leaf temperature, 3) determination of water and temperature stress on the light response parameters, and 4) synthesis and validation.

\section{Progress Prior to 1977}

Both a portable porometer (see reprint by Bingham and Coyne, 1977, appended) and a dual cuvette system were developed and field tested prior to 1977 . These 
systems represent state-of-the-art technology and have been very effective in providing the needed data base. Sampling techniques were worked out for obtaining light response data and low-level. 3-parameter models were selected and tested for describing the photosynthesis and stomatal response functions. A study site was chosen, study trees were selected, scored and grouped into oxidant damage classes.

\section{Progress in 1977}

\section{Tasks carried out:}

The primary task for 1977 was to establish the seasonal course of photosynthesis and stomatal response to light for various oxidant damage classes during the principal period of growth and oxidant exposure (May to October). This involved monthly sampling periods of 7 to 10 days duration. A secondary task was to conduct a laboratory study of the effects of water stress and ozone stress interactions on photosynthesis.

\section{Tasks deferred:}

The water $\mathrm{x}$ ozone stress interaction experiment was originally envisioned to include assessment of the response of internal abscissic acid levels. Since water stress effects on stomatal function are correlated with abscissic acid levels, we wanted to determine what additional effect ozone might have on this hormone with the hope that it would help explain some of the observed responses of stomates to ozone. We also wanted to know if abscissic acid could be useful as a bioassay for oxidant damage. This task was deferred because the other portions of the experiment were more time consuming than originally envisioned. We had also intended to begin modifying existing photosynthes is process models to incorporate oxidant stress effects. Funds intended to support this effort 
were required for support of field personnel and operations and also for additional laboratory analyses. However, a related effort was supported by the geothermal program (see Part III). While not specifically related to oxidant and ponderosa pine, the approach is similar and the results will be directly applicable to the pine data.

\section{Tasks added:}

1. We took advantage of an opportunity to test our approach (instrumentation, sampling data reduction models) for a much different set of conditions involving an agronomic species (snap bean) and a different pollutant $\left(\mathrm{H}_{2} \mathrm{~S}\right)$. Fumigated plant material was made available to us by a geothermal project (see Part II) and we characterized photosynthesis and stomatal light response as a function of $\mathrm{H}_{2} \mathrm{~S}$ alone and $\mathrm{H}_{2} \mathrm{~S}$ plus ozone.

2. The National Science Foundation is supporting development of a miniaturized $\mathrm{CO}_{2}$ sensor which has direct application to our San Bernardino study (concept study appended). We found in 1976 that $\mathrm{CO}_{2}$ concentrations varied directly with ozone levels and that $60 \mathrm{ppm}$ enrichment was possible during daylight hours. This immediately raised a question concerning the possible amelioration of oxidant effects on primary productivity by elevated ambient $\mathrm{CO}_{2}$ levels. The miniature $\mathrm{CO}_{2}$ sensor will allow real-time measurement of apparent photosynthesis in our porometer. At the present time, we are forced to rely heavily on $\mathrm{C}^{14} \mathrm{O}_{2}$ as a tracer for gross $\mathrm{CO}_{2}$ uptake. In addition, the sensor will allow using the porometer in a steady-state for $\mathrm{CO}_{2}$ at any concentration we choose. Hence, we can directly determine the $\mathrm{CO}_{2}$ response of photosynthesis as a function of oxidant damage. We can also measure $\mathrm{CO}_{2}$ compensation concentrations which 
will allow us to further partition resistances in the $\mathrm{CO}_{2}$ diffusion pathway. Partitioning of diffusion resistances is fundamental to understanding the chronology and point of pollutant impact. It is therefore important to describing mechanisms of pollutant action and for modeling pollutant effects.

3. We obtained the services of Dr. Marion Furr from Paine College through our laboratory's Summer Institute program. During Dr. Furr's residence at LLL, we conducted an experiment to determine the effects of ozone on the $u 1$ trastructure of ponderosa pine needles and cotton leaves. Cotton. was included as a type of control plant since it was conducive to conventional techniques of fixing material for electron microscopy while pine needles were not. It was also included because California is Number 2 in the nation for cotton production and ozone damage to cotton has been observed in the Central valley. Completion of this work is currently in progress at Paine College.

\section{Results}

Included in this section are summaries of (1) the ponderosa pine results for our studies in the San Bernardino National Forest (SBNF) and (2) the photosynthesis - water stress - ozone laboratory experiment. Results of the task dealing with gas exchange of snap bean as a function of $\mathrm{H}_{2} \mathrm{~S}$ and/or ozone have been written up in preparation for publication and a preprint is appended. No results are available yet from the experiment on oxidant effects on leaf ultrastructure. Electron micrographs are still being evaluated by Dr. Marion Furr at Paine College.

\section{Oxidant Related Damage To Ponderosa Pine In The SBNF}

Our study site in the SBNF is at $1530 \mathrm{~m}$ situated on the eastern rim of the South Coast Air Basin. It is subjected to heavy doses of ozone (peak concentrations 
may exceed $60 \mathrm{pphm}$ ) which accumulate beneath the marine inversion layer. We have characterized the site and have noted these features. The site supports an even-aged stand of ponderosa pine that germinated following fire in the midfifties. The trees are growing under very similar conditions of microclimate and fumigation dosage, yet the stand displays a continuum of oxidant damage symptoms ranging from slight to no symptoms to trees that support only a single years growth of chlorotic needles. We have stratified our study trees using a oxidant damage scoring system by Paul Miller (appended). A striking contrast develops between resistant and sensitive individuals. As sensitivity increases, trees retain fewer numbers of needle whorls and the whorls deteriorate with respect to number per tree and needles per whorl. The needles themselves tend to decrease in length and girth as oxidant damage increases but there are enough exceptions that in final analysis, there may be no significant differences. Specific leaf weight does not appear to be significantly different among oxidant damage classes although it definitely increases with needle age among current, one-year, and two-year old needles.

Although needle morphology does not show a strong dependence on oxidant damage, the physiological condition of the needles clearly responds in terms of chlorosis and necrosis. It is also clear that rate of growth is particularly correlated with oxidant damage class. Trees scoring in the "very slight damage" class (see appendix for classification) may have $50 \%$ greater height and stem diameter growth than trees of the same age showing moderate to severe damage. We now have the required data base to characterize the response of photosynthesis and stomatal conductance to 1 ight at $20^{\circ} \mathrm{C}$ and minimal soil water stress 
throughout the principal period of growth and oxidant exposure. We can do this for three separate oxidant damage classes including very slight damage, slight to moderate damage, and moderate to severe damage. We are still in the process of reducing and modeling these data so only general trends will be included in this report.

Maximum rates of $\mathrm{CO}_{2}$ incorporation $\left(\mathrm{P}_{\max }\right)$ at saturating light and photochemical conversion efficiency (PCE) clearly decrease as oxidant damage increases. Divergence among damage classes increases as needle age increases. Preliminary analysis of seasonal trends show that $P_{\max }$ and PCE decline from May through October in a somewhat linear fashion. The seasonal rate of decline in $P_{\max }$ appears to be greater in the more stressed trees, but decline in PCE does not appear to accelerate with oxidant damage.

Both stomatal and residual (mesophyll + carboxylation) resistances in the $\mathrm{CO}_{2}$ diffusion pathway appear to increase with foliar symptom development. Maximum stomatal resistance at high light increases and the light sensitivity during stomatal opening decreases with oxidant stress. However, increased stomatal resistance does not seem to be a stress avoidance mechanism because residual resistance deteriorates even more than stomatal resistance. The end result is that carbon dioxide assimilation efficiency and water use efficiency both decrease with oxidant stress. Even though water loss is reduced from the more damaged needles by partial stomatal closure, the much greater increase in residual resistance decreases $\mathrm{CO}_{2}$ uptake so that water use efficiency is also reduced. In general, oxidant is causing two responses which are having pronounced effects on tree growth rates and survivability. First, photosynthesis per unit 
leaf area or mass is significantly reduced. Second, the number of needles whorls per branch and the needles/whorl is also significantly reduced. Thus, the carbon economy of the oxidant stressed trees is impacted from two levels and the result is an accelerated decline in tree vigor which lowers the trees resistance to secondary pathogen infections finally culminating in death.

The scenario describing the patterns we believe is emerging from our data thus far is this: the ponderosa pine population has a widely varying stress response to oxidant in otherwise similar microenvironments. Differential sensitivity to oxidant is probably largely genetically determined but the mechanisms conferring resistance is not understood. We do not believe our data indicates appreciable stress avoidance through stomatal closure. Oxidizable sites within the needle interior may be more protected in the resistant individuals or perhaps resistant individuals can better allocate resources to maintenance or damage repair.

It does appear that the photosynthes is apparatus of current years' needles is injured in the more sensitive individuals prior to the development of foliar symptoms. Presymptom injury is localized predominantly at the mesophyll and/or carboxylation resistances rather than the stomatal resistance. However, as the needles age and are subjected to repeated oxidant insults, minimal stomatal resistances at saturation irradiances increase, stomatal light sensitivity decreases, and photochemical conversion efficiency declines. By this stage, characteristic symptoms are evident and are manifested as a chlorosis in early symptomatic stages but as a necros is in more advanced stages. In the postsymptom stage, mesophyll and carboxylation resistances increase more rapidly than stomatal resistance in response to oxidant exposure. $\mathrm{CO}_{2}$ assimilation efficiency as well as water use efficiency declines until the needles become parasitic to the tree and abscise. 


\section{Water Relations and Primary Productivity of Ponderosa Pine as a Function of Ozone Stress}

Summary \& Prel iminary Conclusions

As some of the data gathered from this experiment are still being reduced, the following discussion should be regarded as preliminary. The results are so relevant to our research objectives and future plans, however, that we have presented them here in detail. Figures 1 and 2 show the response of a typical control tree and are presented to demonstrate the significance of water stress on stomatal conductance. Figures 3 and 4 summarize the important effects of the oxidant utilizing data from all trees, and Figure 5 illustrates the importance of understanding the hormonal system involved in control of leaf water 10ss. Based on the data, and experience gained in the SBNF, we have reached the following conclusions:

1. In ponderosa pine, stomatal conductance is very sensitive to low lever water stress and begins to decrease when predawn xylem water potentials decrease below -4 bars. At a critical potential (varying between -10 bars in control trees and -14 bars in severely ozone stressed trees) the relationship between water potential and conductance is very steep, with conductance decreasing rapidly to less than $0.07 \mathrm{~cm} / \mathrm{s}$.

2. Stomatal conductance of ozone treated trees was not as sensitive to water stress as that of the control trees. This change in sensitivity appears identical to the osmotic adaptation observed when plants are exposed to repeated cycles of water stress and shifts the critical potential of treated trees by as much as 4 bars. Indications of similar behavior have been observed in the SBNF.

3. The shift in the critical potential with ozone stress and the midday closure response observed during the experiment and in the field suggest that 
a sensitive and active control mechanism is involved in regulating water loss from ponderosa pine. Hormone control theories are discussed and experiments proposed to gain a better understanding of this control system.

\section{Rationale}

A11 terrestrial plants growing in natural conditions are subject to varying degrees of water stress. Water stress is a frequent problem with wild species growing in the arid west where rainfall is seasonal, but also is a problem in other areas where careful irrigation scheduling is not practiced. Plants growing under rainfall regimes often go two to three weeks between rains, which is sufficient to develop significant adverse water stress conditions. Plant water status is extremely important to air pollution effects experiments because of its influence on stomatal conductance. The stomatal conductance of plants growing in an only slightly water-limited condition may be twice as great on a cloudy, humid day as on a clear day with lower relative humidity. For a pollutant that enters the leaf primarily through the stomata and reacts rapidly, the higher stomatal conductance on the cloudy day could approximately double pollutant exposure of the plant. The results reported here are from a preliminary experiment designed to indicate (a) the level of control plant water status exerts on the susceptibility of ponderosa pine to gaseous pollutants and (b) to determine if there are any changes in the water stress control mechanisms of ponderosa pine as a result of a season of ozone exposure.

\section{Methods}

To determine the effects of seasonal ozone exposure to the water relations of mature needles of ponderosa pine, ten $2 \mathrm{~m}$ tall trees growing in well-drained 
55 liter containers were placed in two air conditioned, mylar-covered, greenhouses during the summer of 1977. Both greenhouses were supplied with a high volume of carbon filtered ambient air to minimize water vapor buildup and $\mathrm{CO}_{2}$ depletion. The air within the houses was circulated continually by the air conditioner fans to achieve good mixing and to lower boundry layer resistances to vapor exchange with the needles. Ozone was added to the air circulating system of one of the greenhouses and controlled at $0.2 \mathrm{ppm}$ for 6 hours per day. Fumigation continued daily during the needle elongation stage for three months starting in May. This fumigation dosage (approximately $100 \mathrm{ppm}$-hours) was intended to simulate the seasonal dosage of oxidant at our SBNF study site. The trees were watered automatically with distilled water and nutrient levels were maintained with "evergreen balanced" fertilizer spikes.

After the fumigation period, light response curves for apparent photosynthesis and transpiration were measured on three current and first year needles of all trees. After these measurements were completed, three control and three $\mathrm{O}_{3}$ stressed trees were removed from their automatic watering system and were subjected to a drying cycle. Additional light response curves were measured throughout the drying cycle on water stressed trees, and the wellwatered trees were remeasured at end of the experiment. For the light response measurements, the trees were removed from the greenhouses before dawn and taken to a darkened lab and covered with black cloth so that only those needles in the measurement chamber would be exposed to light. This maintained the xylem water potential of the tree at approximately the predawn level during the entire measurement period. Thus, onty small changes in needle water potential, resulting from resistances to water movement from the branch to the needle and along the needle, were incurred during measurement of each light curve. Xylem pressure 
potential measurements determined with a Scholander-type pressure bomb were made on individual fascicles cut at the fascicle-branch interface.

Light response curves were made on individual needle fascicles using our backpack portable mini-cuvette system (Bingham and Coyne 1977, appended) with the exit air being returned to a conventional infrared $\mathrm{CO}_{2}$ sensor. Steadystate porometry techniques were used to control the concentration of $\mathrm{H}_{2} \mathrm{O}$ and $\mathrm{CO}_{2}(40 \pm 1 \%$ relative humidity and $330 \pm 10 \mathrm{ppm}$ respectively). A11 measurements were made at $20 \pm 0.1 \mathrm{C}$. Light on the needles in the mini-cuvette was varied from $0-1800 \mu \mathrm{E} / \mathrm{m}^{2} \mathrm{~s}$ with only a small change in light quality by using a metal halide lamp with a dimming ballast. Exposed leaf area was calculated from measurements of the needle length and chord (determined using a optical measuring magnifier) using geometric formulas.

\section{Results}

The net effect of changes in xylem water potential on the rate of apparent photosynthesis and transpiration of ponderosa pine is shown in Figure 1 . The top set of curves $(\psi>-3$ bars $)$ show the maximum repeatable photosynthesis and conductance values we observed for the lowest water stress during this experiment. We occasionally see similar values in the field when measurements are made in the early morning, after a heavy rain, with low wind and high relative humidity. The second set of curves $(\psi>-8)$ are more typical of the measurements we have made on we11-watered trees under a moderate evaporative demand. The third set of curves ( $\psi \geq-12$ bars) is typical of trees having moist soil at a deeper level but with dry soil near the surface. The 4 bar xylem potential difference between -8 and -12 bars is extremely significant to the gas exchange of ponderosa pine since it reduces stomatal conductance by $50 \%$. This decrease in stomatal conductance reduces photosynthes is by about $25 \%$ from its normal level and could reduce 
pollutant flux into the needle by as much as $50 \%$. The fourth curve $(\psi \geq-20$ bars) is typical of a tree growing under mid-summer water stress conditions. Note that conductance is reduced another $50 \%$ and photosynthesis has now fallen to about one-third value recorded at $\psi \geq-12$ bars. Pollutant flux, which is a function of the concentration difference between the inside and outside of the leaf, multiplied by the stomatal conductance would have been reduced by another $50 \%$.

It should be noted that these are not the same curves which would be observed under natural conditions with the entire canopy in the light. As light and temperature increased with the diurnal cycle of the sun, stomata on the rest of the tree would also open and the xylem potential would fall rapidly reaching a minimum shortly after solar noon. Curves obtained under natural conditions, therefore, are composites of several variables and cannot be used to stimulate the effects of water stress in a model.

Plots of stomatal conductance and apparent photosynthesis at saturating light and with increasing water stress showed a rather sharp inflection point. This relationship is detailed for a single tree (Figure 2) and summarized for al1 trees (Figure 3 ). We do not fully understand why the curves level off at such low conductances, but this behavior is highly suggestive of the limitations induced by residual resistance (mesophy $11+$ carboxylation) to $\mathrm{CO}_{2}$ flux within the needle. We have observed similar behavior among these various ozone damage classes at our field site. These are changes in the potential photosynthetic capacity of the needles, not changes caused by the immediate presence of $\mathrm{O}_{3}$, since the measurements were made in clean air after fumigation had ceased. At low conductances where the stomata are the chief 
7 imit to conductance (high water stress), the photosynthesis-conductance relationship for all needles had the same slope. However, as oxidant damage to the photosynthetic system increased, the curve deviated from this relationship at increasingly lower levels of apparent photosynthesis. Reduced levels of stomatal conductance in the $\mathrm{O}_{3}$ stressed needles are also evident in Figure 3.

Investigators studying the relationship between plant water stress and stomatal conductance have long sought simple one to one correlation between these variables. The stomata, however, are intimately involved in the total plant response to the environment and, hence respond to many other stresses in addition to water stress. The influence of water stress can more readily be described as an operational limit beyond which stomatal aperature cannot increase. Figure 4 shows the stomatal conductance limits that we observed during this experiment. At the lowest water potential levels, there was no significant difference between the conductance curves, but as the water potential increased (decreasing stress) the conductance curves for the control and ozone stressed trees diverged. This is the kind of difference one would expect if the ozone stressed trees had undergone an osmotic adaption to water stress. The osmotic potential of the vacuoles of guard cells subjected to repeated water stress cycles has been observed to increase allowing the stomata to stay open at significantly lower water potentials. In our experiment, however, care was taken to assume that none of the trees were preconditioned to water stress.

A second and we believe more probable explanation for this change in stomatal response to water stress is that ozone stress triggered the same osmotic adaption 
mechanism normally triggered by water stress. This is feasible if osmotic adaption is controlled by the plant hormone system. The growth regulator abscissic acid (ABA) has been shown to increase dramatically in plant leaves as water stress increases. When $A B A$ is applied to leaf tissue, it results in a rapid partial stomatal closure which is correlated with the concentration applied, but the stomata will gradually reopen when ABA is continually applied. This indicates some degree of adaption has occurred such as increasing tolerance to $A B A$ buildup.

Investigators have also shown that $A B A$ levels are increased by other environmental stresses such as heat and water logging of the root system. We have gathered preliminary data which show similar $A B A$ increases in $0_{3}$ stressed trees. If increasing $A B A$ triggers osmotic adaption, then ozone stress would have a significant impact on a plant's ability to survive in an arid environment. These interrelationships have not been systematically investigated to date, despite the fact that any meaningful transfer of air pollution effects studies to the real world requires a thorough understanding of the stomatal control process. The trend shown in Figure 4 can be interpreted as one more indication that stomatal control and stress adaptation are interfaced through an active control system such as the plant hormone system.

An additional problem which confronts the investigator who attempts to describe stomatal response in the real world is the phenomenon of "midday closure". This term describes the partial closure of stomata during the high evaporative demand portion of the day, which may or may not (depending on conditions) be accompanied by full stomatal recovery as the evaporative demand decreases. This is a well-known phenomenon and several investigators have tried unsuccessfully to deal with it using passive water relations theory. 
The "midday closure" phenomenon can be simulated under controlled conditions. During this experiment, for example, we observed that as the equilibrium xylem potential approached -10 bars in the control trees and -14 bars in the ozone stressed trees, we could induce this same kind of closure. This response made it almost impossible to achieve monotonic light response curves at these water stress levels. At these levels, stomatal conductance would begin to increase with light quite normally until the high light levels were reached, at which point a sudden (minutes) closure would occur resulting in a somewhat bellshaped light response curve. An example of one such an occurrance is Figure 5 . Since only the light on the needle in the chamber was increased, the xylem water potential at the point of fascicle attachment to the branch would have remained essentially unchanged. Thus, the only change in potential would be that resulting from the attachment resistance and flow resistance within the needles themselves. The potential change within the needles in the chamber at the two different light levels should have been quite small. This fact was verified by measuring the xylem potential of surrounding fascicles that were still in the dark and by measuring the potential of the fascicles in the chamber before and after the light change. The water potential differences never exceeded 2 bars and in some cases were as small as 0.7 bars. To get such large changes in stomatal conductance from such small changes in water status indicates some kind of an active trigger level has been reached.

A few investigators have shown good correlations between $A B A$ content and this trigger level but others have not been as successful. The difficulty of analyzing plant hormone samples, the difficulty of setting and controlling a plant leaf at a specific water stress level and the possibility that more 
than one hormone is involved in setting the trigger level have undoubtedly clouded the picture. Techniques and instrumentation have now been developed, however, which can be used to set and control the water potential level of the leaf. In addition, the measurement of $A B A$ in plant tissue has been greatly simplified by the development of high pressure liquid chromatography. These two factors could allow a great deal of this confusion to be eliminated in the near future.

Itai, et al. Ipresented evidence for the hypothesis factors in a control system that facilitates root-shoot communication. The fact that "midday closure" is absent from many plants with ample soil water and that $A B A$ increases in leaves are much easier to induce in detached leaves lends credence to their theory. The extreme difficulty of measuring cytokinin levels in small tissue samples has prevented a full investigation of this idea. We believe that by injecting sma11 amounts of cytokinin into the plant transpiration stream we can adjust the internal $A B A / c y$ tokinin ratio at will and, thereby, provide a means to test this hypothes is about the root-shoot communication mechanism active in stomatal function. This information should greatly improve our ability to mechanistically model plant gas exchange processes and enhance our understanding of this important aspect of air pollution effects on vegetation.

1 Itai, C. A. Richmond and Y. Vaadia, 1968. The Role of Root Cytokinins During Water and Salinity Stress. Isr. J. Bot. 17:187-195. 

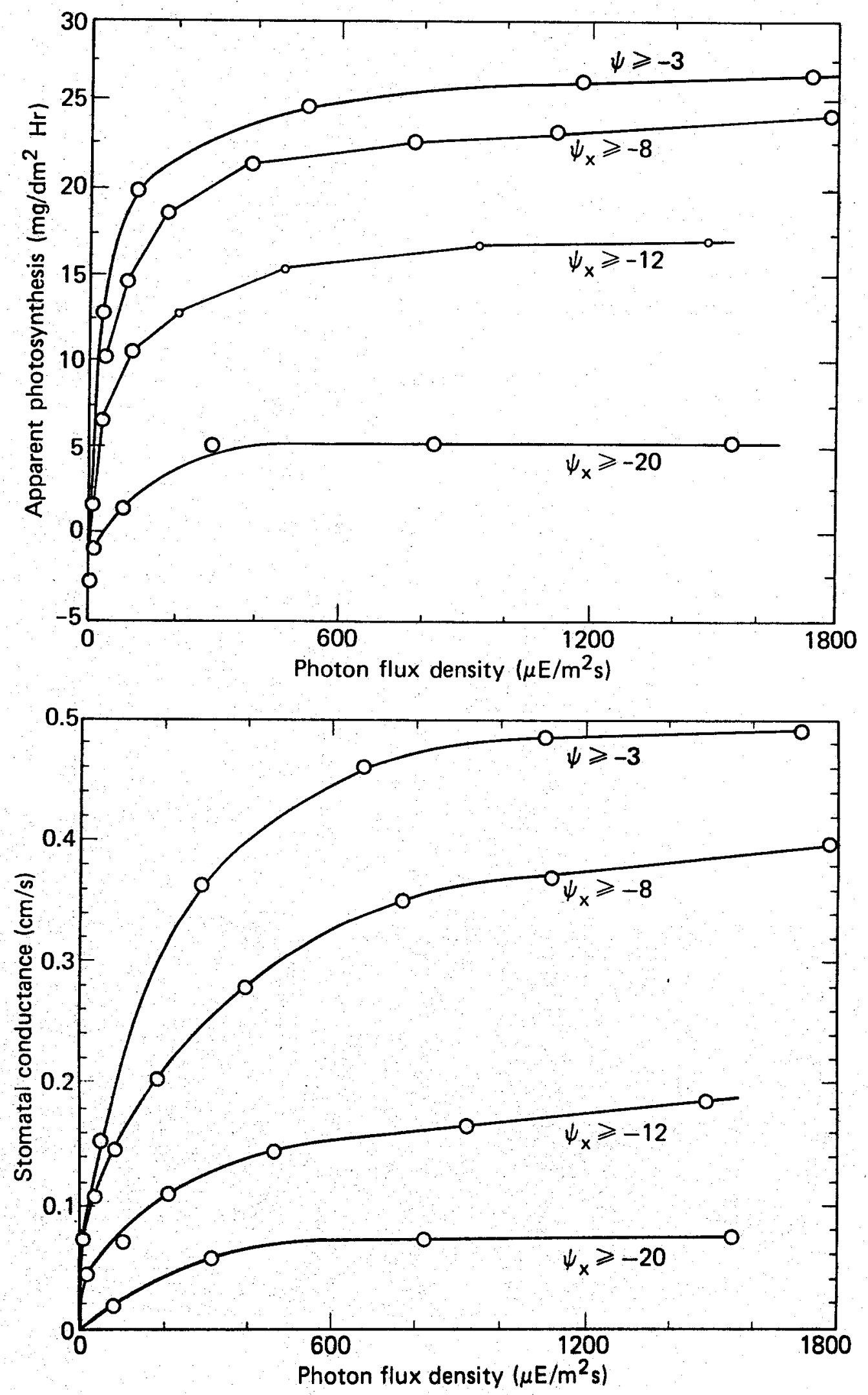

Figure 1 - Typical light response curves for control trees with increasing water stress. Constant potential curves were made by keeping the tree in the dark and exposing only the fascicle being measured to increasing light. 


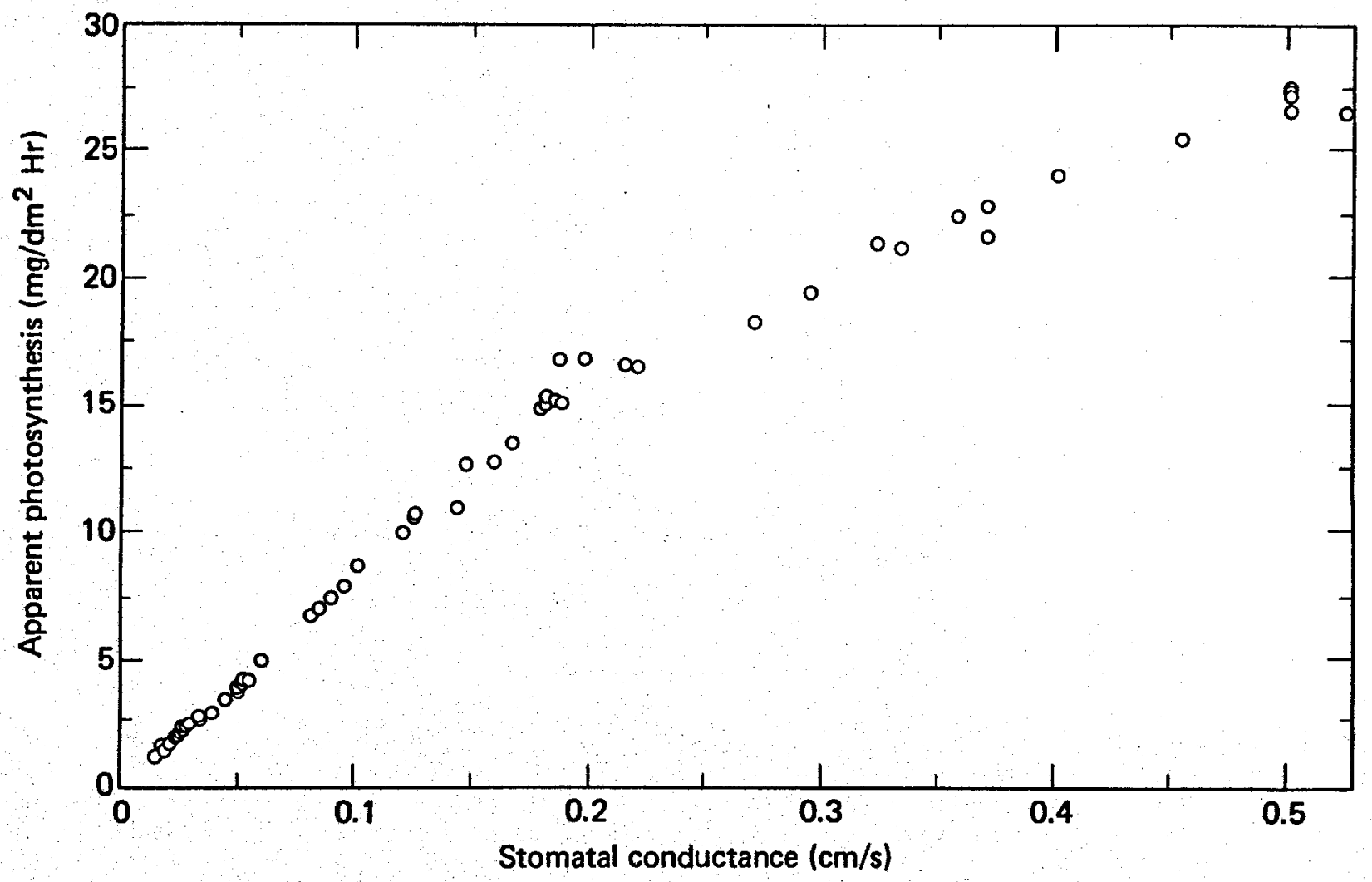

Figure 2 - Typical relationship observed for stomatal conductance and apparent photosynthes is of control trees at saturating light and with increasing water stress. Xylem water potential was varied from -3 bars to -25 bars during these measurements. 


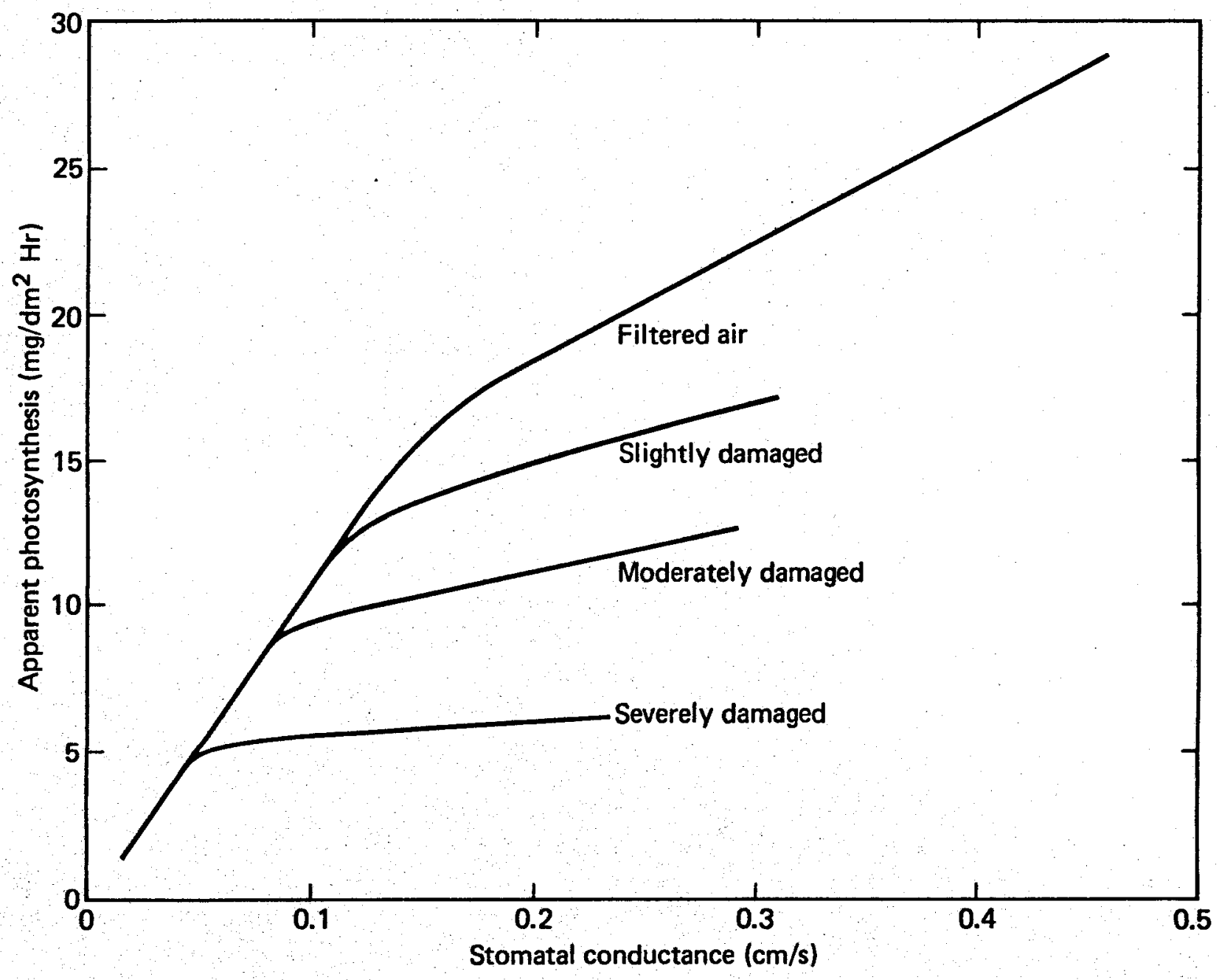

Figure 3 - Relationship of stomatal conductance and apparent photosynthes is for needle fascicles of all trees at saturating light and increasing water stress. Labeled curves are for groups of fascicles with visual damage typical of corresponding damage classes in the Miller (see appendix) rating scheme. 


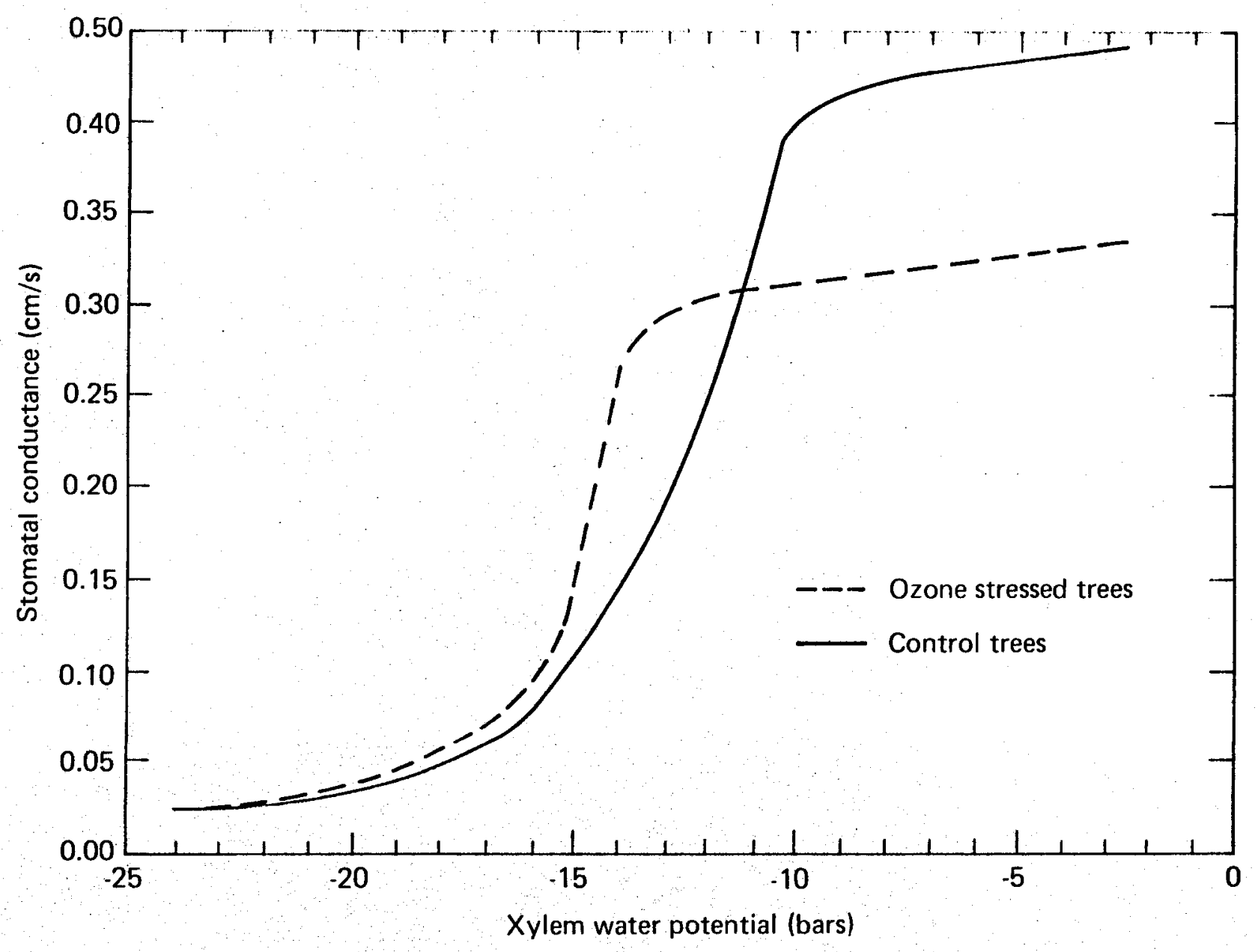

Figure 4 - Response of stomatal conductance to water stress for control and ozone stressed trees. The sharp inflection at -10 bars for control trees and -14 bars for ozone stressed trees is often referred to as the critical potential. 


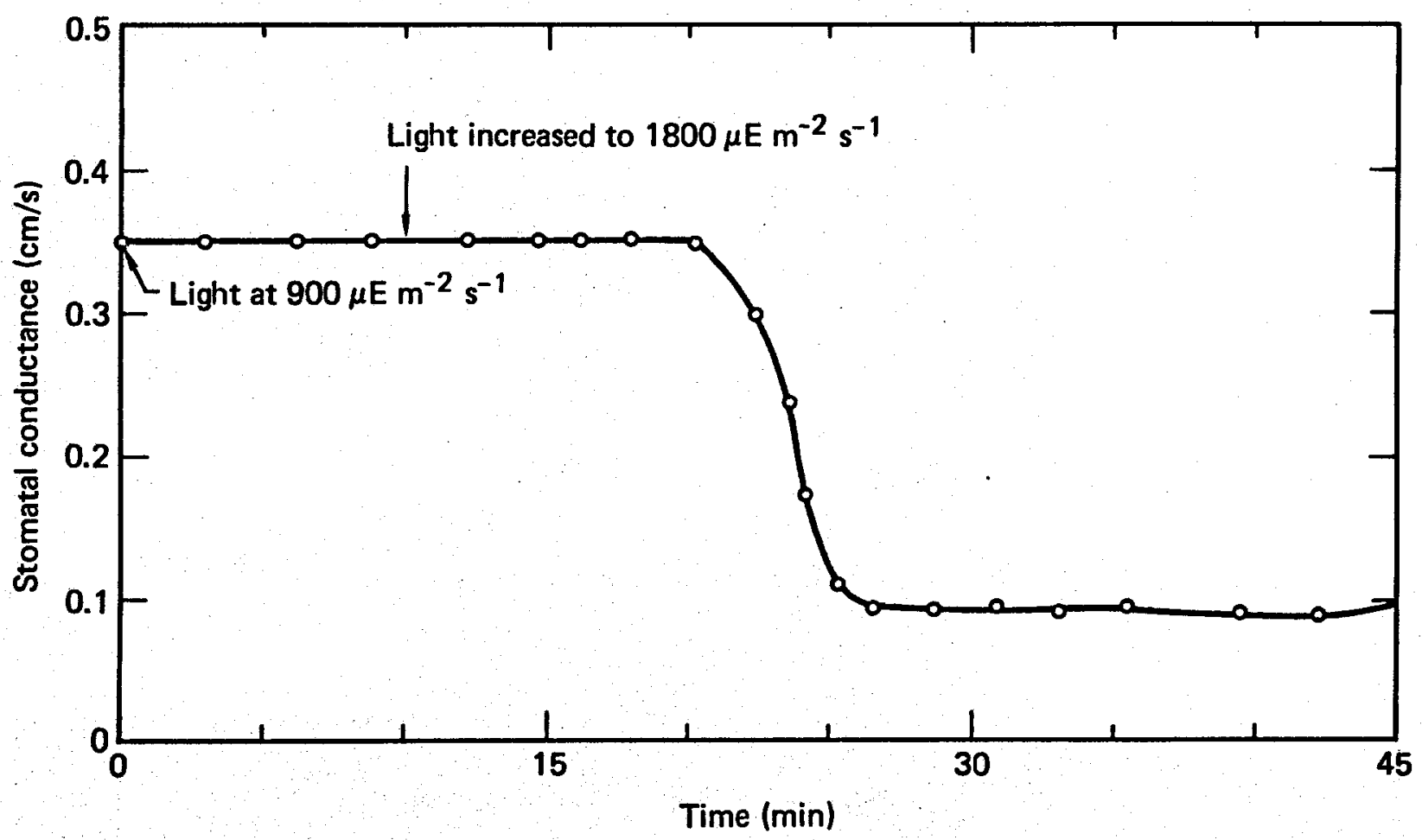

Figure 5 - A laboratory simulation of "midday closure" resulting from decreasing the needle water potential below the critical potential by slightly increasing the evaporative demand. The change in needle water potential from moderate light to high light was typically 1 bar in these experiments. 
II. Air Pollution Effects On Vegetation From Geothermal Development (RPIS \#002342)

\section{Review of Research Scope}

This study is a sub-project of "IVEP Geotherma1: Ecosystem Quality", RPIS \#002342, and comprises about $15 \%$ of the total of those ecological studies. (The Ecosystems Quality program is about $20 \%$ of the total Imperial Valley Environmental Project).

The objective of this study is to assess the susceptibility of Imperial Valley vegetation to geothermal gas emissions. The constraints due to IVEP guidelines are to limit the time required (two years for the field program phases) and to limit the extend of the work to "baseline" studies, which implies that only a screening of air pollutants and gross dose-response characteristics are possible.

There are three tasks to this study as follows:

Task 1 - To screen Crop Plants for Growth Reduction Under Chronic Exposure Conditions to Determine the Worst Case Dose-Response

This task is a sub-contract to extend work that had begun at University of California - Riverside, under an NSF-RANN grant. The chronic, 24-hour per day fumigation with $\mathrm{H}_{2} \mathrm{~S}$ is carried out in enclosed greenhouses on several Imperial Valley crops in culture media. These are the worst possible conditions for injury because diffusion resistance to $\mathrm{H}_{2} \mathrm{~S}$ is low and there is no intermittency to the exposure that would permit metabolic recovery from the stress. The investigators are C. Ray Thompson and Gerrit Kats of the Statewide Air Pollution Research Center, University of California, Riverside. 
Task 2 - To Determine Physiological Response (Photosynthesis and Diffusion Resistance) in Exposures Simulating Field Conditions So That Modes of Toxicity May be Included in Process Models for Assessment

The controlled fumigations are carried out in open-top chambers in the field by LLL personnel on a few key crops. Photosynthesis and leaf diffusion resistance are measured by gas exchange techniques in leaf diffusion porometers. The investigators are Gail E. Bingham, Patrick I. Coyne, and Joseph H. Shinn.

Task 3 - To Determine Growth, Allocation, and Yield Reduction for a Bioassay Crop in Exposures Simulating Field Conditions With Combined Stress of $\mathrm{H}_{2} \mathrm{~S}$ and Photochemical Smog

This task is a joint effort by LLL and a sub-contract to University of California, Davis, conducted at the University Farm. The chronic, 4-hour per day fumigations are carried out in special open-top chambers combining $\mathrm{H}_{2} \mathrm{~S}$ and $\mathrm{O}_{3}$ exposures on the bioassay plant Phaseolus vulgaris $\underline{L}$ with continuous observations of growth and phenology. Investigators are Joseph H. Shinn and James P. Bennett (U.C. Davis, Department of Vegetable Crops).

\section{Progress Prior to 1977}

Task 1:

Previous studies by the investigators were conducted on four species of vegetation: alfalfa (Medicago sativa $L$ ), Thompson seedless grapes (Vitis vinifera), California buckeye (Aesculus california) and Ponderosa pine (Pinus ponderosa); showed that continuous fumigation with $0,0.03,0.30$, and $3 \mathrm{ppm}$ $\mathrm{H}_{2} \mathrm{~S}$ caused injury to all species at the two highest levels with alfalfa and grapes being the most sensitive. No deleterious effects were seen at $0.03 \mathrm{ppm}$ 
(the California Air Quality Standary based on human olfactory response criteria). Later work showed a decided stimulation in growth of both lettuce and sugar beets at the $0.03 \mathrm{ppm}$ level.

\section{Task 2:}

The first exposures of Imperial Valley crop plants in the field were conducted by LLL in January-February 1976 at the USDA Imperial Valley Conservation Research Center, using Boyce Thompson Institute-type, circular, opentop chambers. Lettuce and sugar beets were exposed for 3-hour periods at mid-day to a simulated geothermal pollutant gas mixture $15 \mathrm{CO}_{2}: 1 \mathrm{H}_{2} \mathrm{~S}: 1 \mathrm{CH}_{4}$ : $2 \mathrm{~N}_{2}$ parts by volume added to air. It was found that the $0.5 \mathrm{ppm} \mathrm{H}_{2} \mathrm{~S}$ (plus the above mixture) significantly stimulated photosynthesis and decreased leaf diffusion resistance. The first significant level of injury (10-20\% reduction of photosynthesis) was between $2 \mathrm{ppm}$ and $5 \mathrm{ppm} \mathrm{H}_{2} \mathrm{~S}$. This lower sensitivity to $\mathrm{H}_{2} \mathrm{~S}$ in the mixture for the field studies occurred at concentration an order of magnitude higher than those observed under the worst case conditions in Task 1 and it is believed to be due to higher leaf diffusion resistance and greater metabolic vitality of the field-grown plants.

\section{Task 3:}

This effort was not initiated until 1977.

\section{Progress in 1977}

Task 1:

The method of fumigation was altered slightly so that the levels of chronic, continuous exposure to $\mathrm{H}_{2} \mathrm{~S}$ (alone) were $0,0.03,0.10$, and $0.3 \mathrm{ppm}$. Two new 
treatments added were $0.3 \mathrm{ppm} \mathrm{SO}_{2}$ and $0.3 \mathrm{ppm} \mathrm{H}_{2} \mathrm{~S}+50 \mathrm{ppm} \mathrm{CO}_{2}$. It was found that for four Imperial Valley crops (lettuce, sugar beets, alfalfa, and cotton) growth was significantly stimulated at concentrations of $\mathrm{H}_{2} \mathrm{~S}$ (alone) up to $0.1 \mathrm{ppm}$. The first significant level of injury for these four crops is about $10-20 \%$ reduction of foliage dry weight taken over the whole growing period at chronic exposures of $0.3 \mathrm{ppm} \mathrm{H}_{2} \mathrm{~S}$. Cotton boll and flower production were not injured but sugar beet roots were injured at this level, $0.3 \mathrm{ppm} \mathrm{H}_{2} \mathrm{~S}$. Alfalfa harvested in stages (cuttings) showed steadily decreasing foliage productivity from the third cutting through the sixth and final cutting during the continuous exposure to $0.3 \mathrm{ppm} \mathrm{H}_{2} \mathrm{~S}$. The addition of $50 \mathrm{ppm} \mathrm{CO} 2$ was sufficient to overcome all the loss of dry weight in the exposure to $0.3 \mathrm{ppm} \mathrm{H}_{2} \mathrm{~S}$ of sugar beets, cotton, and alfalfa, but for lettuce $50 \mathrm{ppm} \mathrm{CO}_{2}$ did not eliminate the injury even though it significantly reduced it. In comparing the effects of equal treatments of $\mathrm{H}_{2} \mathrm{~S}$ and $\mathrm{SO}_{2}$ (0.3 ppm continuous exposures) it was found that statistically they had the same effect on dry matter production of sugar beets (for lettuce, no conclusions could be drawn). The investigators have provided a final report and submitted a manuscript for publication at the study termination, October 1977.

\section{Task 2:}

A new type of exposure facility was designed in the form of a linear exposure-gradient, open-top chamber which retains the portability and low cost of the circular, open-top chambers, but affords greater possibility of statistical analysis of dose-response data because of the continuous horizontal gradient of exposure rate. Sixteen of these chambers were constructed and 
utilized in a study of combined effects of $\mathrm{H}_{2} \mathrm{~S}$ and $\mathrm{O}_{3}$ on snap beans (Phaseolus vulgaris $\underline{L}$ ) at the University Farm at Davis. Bingham and Coyne (See Tasks added, Part I) determined that after 3 weeks of exposure, 4 hours per day, the photosynthesis and diffusive conductance are significantly stimulated at $0.74 \mathrm{ppm}$ $\mathrm{H}_{2} \mathrm{~S}$. The addition of $0.07 \mathrm{ppm}_{3}$ to $0.74 \mathrm{ppm} \mathrm{H}_{2} \mathrm{~S}$ is sufficient to overcome this stimulation and even cause significant depression of photosynthesis. Exposure to 3 to $5 \mathrm{ppm} \mathrm{H} \mathrm{H}_{2} \mathrm{~S}$ caused depression of photosynthes is even without ozone present, confirming the prior observations made on sugar beets and lettuce. Two manuscripts have been submitted for publication, one describing the exposure facility and the other on the topic of physiological responses. This task is now concluded.

\section{Task 3:}

The study of the combined effects of $\mathrm{H}_{2} \mathrm{~S}$ and $\mathrm{O}_{3}$ were also investigated in terms of phenology and biomass changes during a 24-day period of 4-hour per day exposures of snap beans at University of California, Davis. A sub-contract to Dr. James P. Bennett and his assistant, Kathy Barnes, provided growth observation and interpretation of data. Leaf injury scores, numbers of leaves, and flower phenology were observed through the growing period until pod set. Measurements of economic yield, bioyield, leaf area, branch, raceme, and pod number were made at market maturity. Total biomass was also measured one week after ending fumigations. Total dry weight, pod dry weight, and leaf area were significantly reduced at chronic $\mathrm{H}_{2} \mathrm{~S}$ levels greater than $3 \mathrm{ppm}$ (about $285 \mathrm{ppm}$ hours). The addition of $0.07 \mathrm{ppm}$ ozone caused significantly greater injury than $\mathrm{H}_{2} \mathrm{~S}$ alone 
at $3 \mathrm{ppm} \mathrm{H}_{2} \mathrm{~S}$ but a higher concentrations of $\mathrm{H}_{2} \mathrm{~S}$ the combined effect of $\mathrm{H}_{2} \mathrm{~S}$ an ozone was not significantly different than $\mathrm{H}_{2} \mathrm{~S}$ alone. At exposure concentrations lower than $3 \mathrm{ppm} \mathrm{H}_{2} \mathrm{~S}$, there was no detectable effect on growth. Furthermore, after the 24-day fumigation was terminated the plants recovered sufficiently to produce the same yield (pod weight) even where exposure concentrations were about $5 \mathrm{ppm} \mathrm{H}_{2} \mathrm{~S}$. The resulting lower sensitivity to $\mathrm{H}_{2} \mathrm{~S}$ observed in the field compared to the greenhouse study of Task 1 is confirmed in this experiment. The investigators have submitted a manuscript for publication. A study comparing $\mathrm{H}_{2} \mathrm{~S}$ and $\mathrm{SO}_{2}$ will be completed by comparing growth and allocation of the bioassay crop Phaseolus vulgaris, in two successive studies at the University Farms at Davis, California. Comparison of $\mathrm{H}_{2} \mathrm{~S}$ response to $\mathrm{SO}_{2}$ response under the same set of conditions will verify the hypothesis that the major differences in plant physiological responses to the gases is due to the conductance and solubility of the gases in the tissue. If this is true, future work would be necessary to test the hypothesis, but in the meantime known comparative sensitivity of species to $\mathrm{SO}_{2}$ could be useful in $\mathrm{H}_{2} \mathrm{~S}$ assessments. 
III. Regional Assessment of Air Pollution Impact on Vegetation by Mathematical Modeling

\section{Review of Scope of Work}

The regional assessment of air pollution effects on vegetation is a subproject of "IVEP Geothermal: Integrated Assessment" (RPIS \#002349) consisting of about $15 \%$ of that assessment effort. The research is usually not reviewed by DBER Environmental Programs, however, at LLL it is closely interactive with the research reported under Parts I and II and consequently it is being reported here.

The objective of this project is to implement the model as a tool that integrates experimental data to reliably predict geothermal air pollutant impacts on crop yield. The modeling effort is divided into developing process models and seasonal growth models. This model heirarchy relies heavily on models already in the literature with substantial improvement and modification to include biochemical mechanisms of toxic air pollutants. Other models are limited in many respects, and our goal is to eliminate these limitations, and to implement the modeling effort in a relevant and meaningful way. As an integrating tool, the models provide the means to design field research and prioritize data collection to insure completeness of the data set. By performing sensitivity analyses, the critical measurement parameters are pinpointed. Finally, the modeling is a focus to conceptualize hypotheses which explain the plant responses.

\section{Progress Prior to 1977}

This work was not supported prior to 1977. The principal investigator (Kercher) was responsible for several related studies both at Oak Ridge National 
Laboratory and LLL listed below:

(1) J. R. Kercher and H. H. Shugart, Jr. Trophic Structure, Effective Trophic Position and Connectively in Food Webs. American Naturalist 109: 197-206, 1975.

(2) J. R. Kercher and R. A. Goldstein. Vegetational Analysis by Canonical Correlation of Species and Environmental Parameters. Vegetatio 35: $153-163,1977$.

(3) J. R. Kercher. Mathematical Methods of Analys is of Linear Models: A Documentation of the Linear Ecosystem Analysis Package (LEAP). EDFB-IBP 75-6, ORNL, Oak Ridge, Tennessee.

(4) D. L. Ermak, J. R. Kercher, and R. L. Ritschard. A Comprehensive Approach For Evaluating the Environmental and Human Health Effects of Coal-Fired Electricity Production in the Southwest. In Proc. Disturbed Lands Reclamation and Use in the Southwest (1975), University of Arizona Press, Tucson, 1977.

\section{Progress in 1977}

A model of photosynthesis and growth under gaseous sulfur pollutant stress was developed (GROW 1) (Report appended). The model simulates photosynthesis as a function of such variables as irradiance, $\mathrm{CO}_{2}$ diffusional resistances, and internal biochemical processes. The model allocates the products of photosynthesis to structural (leaf, stem, root, and fruit) and to storage compartments of the plant. The simulations encompass the entire growing season from germination to senescence. Examples were calculated for various levels of pollutant stress. Dose-yield curves are being constructed as a useful assessment of crop yield. 
In addition to obtaining an assessment tool, the new scientific accomplishments in 1977 were (1) the demonstration that valid predictions of yield loss (economic loss) could be made from our present understanding of phytotoxicant depression of photosynthesis and allocation strategies, (2) consequentiy, the observations of a high threshold for $\mathrm{H}_{2} \mathrm{~S}$ depression of photosynthesis (Shinn, et al.; Task 2 of Part II) compared to a low threshold for $\mathrm{H}_{2} \mathrm{~S}$ depression of growth in a greenhouse (Thompson and Kats; Task 1 of Part II) could be completely reconciled and explained by differences in diffusive conductance and metabolism, (3) the field measurements of photosynthes is should also include the $\mathrm{CO}_{2}$-response of the plants to be a fully complete data set, and (4) some plants will have a sensitive response to a pollutant stress in the forms of reduced root growth which may not be evident to field observers.

A forest succession model based on the Botkin model JABOWA was implemented at LLL, which includes the species interactions of shading and crowding and includes response to environmental factors. However, this model is not adequate for western coniferous forests in which fire ecology is important and water is a limiting factor.

The models developed will be utilized in an Integrated Assessment scenario for Imperial Valley, California, where varying development alternatives will be played-off and the effects of $\mathrm{H}_{2} \mathrm{~S}$ emissions on the agricultural industry ( $\$ 500$ million annually) will be determined.

Extensive future development and research for this modeling effort is not likely to continue under Integrated Assessment. 


\section{PUBLISHED PAPERS}

Bingham, G. E., and P. I. Coyne, 1977. A Portable, Temperature-Controlled, Steady-State Porometer for Field Measurements of Transpiration and Photosynthesis. Photosynthetica 11 (1): 148-160.

Coyne, P. 0., and G. E. Bingham, 1977. Carbon Dioxide Correlation With Oxidant Air Pollution In The San Bernardino Mountains of California. Air Pollution Control Assn. J. 27 (8): 782-784.

Shinn, J. H.,B. R. Clegg, M. L. Stuart, and S. E. Thompson, 1976. Exposures of Field-Grown Lettuce to Geothermal Air Pollution: Photosynthetic and Stomatal Responses. J. Env. Sci. Health A11: 603-612.

\section{PAPERS SUBMITTED}

Bennett, J. B., K. Barnes, and J. Shinn. Interactive Effects of $\mathrm{H}_{2} \mathrm{~S}$ and $\mathrm{O}_{3}$ On The Yield of Snap Bean (Phaseolus vulgaris L). New Phytologist.

Coyne, P. I., and G. E. Bingham, Photosynthesis and Stomatal Light Responses In Snap Beans Exposed to Hydrogen Sulfide and Ozone. New Phytologist.

Shinn, J. S., B. R. Clegg, and M. L. Stuart. A Minimum Field Fumigation Method for Exposing Plants to Controlled Gradients of Air Pollution Levels. J. Env. Quality.

Thompson, C. R., and G. Kats. Effects of Continuous $\mathrm{H}_{2} S$ Fumigation on Crop and Forest Plants. Env. Sci. Tech. 
REPORTS

Bingham, G. E. and J. H. McQuaid, 1977. Concept Study For A Miniaturized Rapid-Response Infrared Sensor For Low Carbon Dioxide Concentrations. UCRL-52221, Lawrence Livermore Laboratory, Livermore, California.

Kercher, J. R. GROW 1: A crop Growth Mode1 For Assessing Impacts of Gaseous Pollutants From Geothermal Technologies. UCRL-52247. Lawrence Livermore Laboratory, Livermore, California.

Thompson, C. R. and G. Kats, 1977. Effects of $\mathrm{H}_{2} \mathrm{~S}, \mathrm{H}_{2} \mathrm{~S}+\mathrm{CO}_{2}$ and $\mathrm{SO}_{2}$ On Lettuce, Sugar Beets, Alfalfa, and Cotton. Final Report for Lawrence Livermore Laboratory, Statewide Air Pollution Research Center, University of California, Riverside, California 92521. 


\section{MANUSCRIPTS IN PREPARATION}

(Not available for distribution)

Bingham, G. E., and P. I. Coyne. Influence of Water Stress On Ozone Damage to Photosynthesis and Stomatal Function in Ponderosa Pine.

Coyne, P. I., and G. E. Bingham. $\mathrm{C}^{14} \mathrm{O}_{2}$ Uptake and Needle Diffusional Resistance in Relation to Ozone Damage in Ponderosa Pine.

Furr, M., P. I. Coyne, and G. E. Bingham. Effects of Ozone On Leaf U7trastructure in Ponderosa Pine and Cotton.

Kercher, J. R. A Leaf Model of Photosynthesis Under the Influence of Simple Gaseous Sulfur Compounds $\left(\mathrm{H}_{2} \mathrm{~S}\right.$ and $\left.\mathrm{SO}_{2}\right)$ 


\section{PAPERS PRESENTED AT SCIENTIFIC MEETINGS}

Bennett, J. P. and J. H. Shinn, 1977. Snap Bean Yield and Partitioning Responses to Ozone and Hydrogen Sulfide Exposures in the Field. Agronomy Abstracts, p.96. Presented at 69th Annual Meeting, American Society of Agronomy, Los Angeles, November 1977.

Bingham, G. E., P. I. Coyne, J. P. Bennett, and J. H. Shinn, 1977. Photosynthesis and Stomatal Resistance Response to Ozone and/or Hydrogen Sulfide Exposures in Field Grown Snap Beans. Agronomy Abstracts, p. 97. Presented at 69th Annual Meeting, American Society of Agronomy, Los Angeles, November 1977.

* Kercher, J. R. A Model of Photosynthes is and Growth in Plants Under Stress by Gaseous Pollutants. Bull. Eco. Sco. Am. 57, No. 1, p. 36 (1976). 1976 Annual Meeting of the Ecological Society of America. AIBS meeting, New Orleans, May 30- June 3, 1976.

*Kercher, J. R. Simulations of Effects of Geothermal Pollutants on Crop Growth Using a Computer Plant Model. Bul1. Eco. Soc. Am. 58 No. 2, p. 56, 1977. Annual Meeting of the Ecological Society of America. AIBS meeting, East Lansing, Michigan, August 27- August 25, 1977.

* Indicates research funded by LLL-RPIS No. 002349, RK-01-03-03, IVEP Geothermal Integrated Assessment. 


\section{EXTRACURRICULAR INVOLVEMENT}

Patrick I. Coyne - Participated in federal inventory of energy related research to categorize projects according to Environmental Health and Safety Issues and Requirements. Participation requested by DBER/ERDA. 
SCORING SYSTEM FOR OXIDANT DAMAGE

(P. R. Miller 1973)

CHARACTERISTIC:

SCORE

Needle Retention (Number of Years Retained)

Upper Crown.

0 Ranging up to 6

Lower Crown.

0 Ranging up to 6

Needle Condition (one score value given to each annual whor 1 )

Upper Crown

Green

4

Chlorotic Mottle

Uniform Yellow or Necrosis

0

Lower Crown

Green

4

Chlorotic Mottle

Uniform Yellow or Necrosis

Needle Length (Upper and Lower Crown)

Average Expected Length

Less Than Expected Length

Branch Mortality (Lower Crown)

Normal Mortality

Pronounced Mortality

\section{CATEGORIES}

\section{SCORE RANGE}

0

1-8

$9-14$

15-21

$22-28$

$29-35$

$36+$
DESCRIPTION

Dead

Very Severe Damage

Severe Damage

Moderate Damage

Slight Damage

Very Slight Damage

No Visible Symptoms 
- 37 -

APPENDED PUBLICATIONS ARE IN SEPARATE BINDER 


\section{CONTENTS}

Bingham, G. E., and P. I. Coyne, 1977. A Portable, Temperature-Controlled, Steady-State Porometer for Field Measurements of Transpiration and Photosynthesis. Photosynthetica 11 (1): 148-160.

Coyne, P. I., and G. E. Bingham, 1977. Carbon Dioxide Correlation With Oxidant Air Pollution in the San Bernardino Mountains of California. Air Pollution Control Assn. J. 27 (8): 782-784.

Shinn, H. H., B. R. Clegg, M. L. Stuart, and S. E. Thompson, 1976. Exposures of Field-Grown Lettuce to Geothermal Air Pollution: Photosynthetic and Stomatal Responses, J. Env. Sci. Health A11: 603-612.

Bennett, J. B., K. Barnes, and J. Shinn. Interactive Effects of $\mathrm{H}_{2} \mathrm{~S}$ and $\mathrm{O}_{3}$ on the Yield of Snap Bean (Phaseolus vulgaris L). New Phytologist.

Coyne, P. I., and G. E. Bingham, Photosynthesis and Stomatal Light Responses in Snap Beans Exposed to Hydrogen Sulfide and Ozone. New Phytologist.

Shinn, J. S., B. R. Clegg, and M. L. Stuart. A Minimum Field Fumigation Method for Exposing Plants to Controlled Gradients of Air Pollution Levels. J. Env. Quality.

Thompson, C. R., and G. Kats. Effects of Continuous $\mathrm{H}_{2} \mathrm{~S}$ Fumigation on Crop and Forest Plants. Env. Sci. Tech.

Bingham, G. E. and J. H. McQuaid, 1977. Concept Study for a Miniaturized Rapid-Response Infrared Sensor for Low Carbon Dioxide Concentrations. UCRL-52221, Lawrence Livermore Laboratory, Livermore, California.

Kercher, J. R. GROW 1: A Crop Growth Model for Assessing.Impacts of Gaseous Pollutants From Geothermal Technologies. UCRL-52247. Lawrence Livermore Laboratory, Livermore, California.

Thompson, C. R. and G. Kats, 1977. Effects of $\mathrm{H}_{2} \mathrm{~S}, \mathrm{H}_{2} \mathrm{~S}+\mathrm{CO}_{2}$ and $\mathrm{SO}_{2}$ on Lettuce, Sugar Beets, Alfalfa, and Cotton. Final Report for Lawrence Livermore Laboratory, Statewide Air Pollution Research Center, University of California, Riverside, California 92521. UCRL-13790 


\section{NOTICE}

"This report was prepared as an account of work sponsored by the United States Government Neither the United States nor the United States Department of Energy, nor any of their em ployees, nor any of their contractors, subcontractors, or their employees, makes any warranty. express or implied, or assumes any legal liability or responsibility for the accuracy, completeness or usefulness of any information, apparatus, product or process disclosed, or represents that its use would not infringe privately-owned righ ts."

\section{NOTICE}

Reference to a company or product name does not imply approval or recommendation of the product by the University of California or the U.S. Department of Energy to the exclusion of others that may be suitable

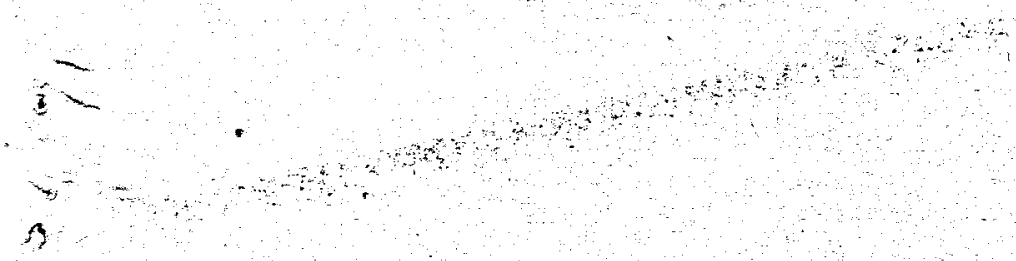

